\title{
Valuing the Spiritual
}

\author{
Eric J. Hall ${ }^{1}$ (D) Richard A. Powell ${ }^{2}$
}

Accepted: 5 February 2021 / Published online: 21 February 2021

(c) The Author(s), under exclusive licence to Springer Science+Business Media, LLC part of Springer Nature 2021

\begin{abstract}
Identifying reforms that minimize US healthcare costs is imperative. This commentary explores one intervention with potential cost-saving implications that has received comparably minimal consideration: spiritual care provision. It highlights the staff and patient costing benefits of spiritual care in addressing spiritual distress and urges practical policy and research initiatives to maximize its impact.
\end{abstract}

Keywords Spiritual $\cdot$ Care $\cdot$ Health $\cdot$ Provider $\cdot$ Costs

\section{Introduction}

In 2018, North Americans spent $\$ 3.65$ trillion- $\$ 11,121$ per person-on health care (Herman 2019), considerably more than any of the other 35 developed OECD (Organization for Economic Co-operation and Development 2017) countries; an expenditure level not reflected in US patient health outcomes compared to other similarly wealthy and sizeable nations (Sawyer and McDermott 2019). Forecasts indicate this $4.4 \%$ increase on 2017 will be exceeded by an average annual growth rate of $5.5 \%$ between 2018 and 2027, by when health care will be one-fifth of the country's gross domestic product (Sisko et al. 2019). Identifying reforms that minimize costs is imperative. One intervention with potential cost-saving implications that has received comparably minimal consideration is spiritual care provision.

Eric J. Hall

ejhall@healthcarechaplaincy.org

http://www.healthcarechaplaincy.org

Richard A. Powell

r.powell@imperial.ac.uk

1 HealthCare Chaplaincy Network and Spiritual Care Association, 505 8th Ave, 9th floor, New York, NY 10016, USA

2 Department of Primary Care \& Public Health, Imperial College London, NIHR Applied Research Center Northwest London, Charing Cross Campus, The Reynolds Building, St Dunstan's Road, London, England 
Spirituality can be an elusive concept to many, including in the health field, especially regarding its operationalization. It is defined as an intrinsic aspect of humanity through which people seek ultimate meaning, purpose and transcendence and experience a relationship to self, family, others, community, society, nature and the significant or sacred (Puchalski et al. 2014). It is expressed through beliefs, values, traditions and practices (Puchalski et al. 2014). Spiritual distress occurs when there is an impaired ability to experience and integrate this meaning and purpose in one's life that can impact a patient's health status, which spiritual care-which in the USA is provided by multi-denominational chaplains - seeks to address.

Evidence shows that for a significant proportion of physically or mentally ill patients, spirituality can provide coping and resources, enhance pain management, improve surgical outcomes, protect against depression and reduce the risk of substance abuse and suicide (Larson and Larson 2003). For example, patients not receiving adequate spiritual support are less likely to receive a week or more in hospice and are more likely to die receiving aggressive intensive care unit (ICU) care (Flannelly et al. 2012). In this way, spirituality is often a coping strategy, with prayer, meditation and mindfulness among the spiritual resources patients employ to help cope with their illness. The potential magnitude of this positive impact is extensive; studies of patients' beliefs show $87 \%$ consider spirituality important in their lives (Hills et al. 2005), while 51-77\% consider religion is important (Balboni et al. 2007).

The prevalence of beliefs and the potentially beneficial impact of spiritual care mean meeting the spiritual needs of patients, which can have financial benefits to health systems. These benefits can be achieved via healthcare staff as well as via patients.

\section{Staffing Cost Benefits}

One of the unique aspects of US chaplaincy care is chaplains are explicitly charged with bringing spiritual care not just to patients and their loved ones, but also to other care providers. Chaplains provide proactive spiritual and emotional support to colleagues to cope with the intensity of their profession, and healthcare professionals are more likely to foster resilience, which leads to better professional engagement and quality of patient care provided (Lumb 2016).

Moreover, studies show significant problems with compassion fatigue and burnout among providers across disciplines with consequences that will escalate dramatically in the coming years (Kamal et al. 2019), particularly when one considers the effects of pandemics (e.g., SARS, Swine Flu, Avian Flu, COVID-19). Shanafelt et al. found $45.8 \%$ of US doctors exhibit one or more symptoms of burnout, with physicians-in-training scoring much higher (76\%) (Shanafelt et al. 2002). Such burnout can lead to physician error-with potentially litigious repercussionswhich can in turn contribute to further burnout and also impact the physician's ability to communicate empathically with patients and their loved ones (Ratanawongsa et al. 2008). Given the potential human and monetary costs of medical mistakes, 
the emotional impact of actual or perceived errors can be devastating for physicians (Spickard et al. 2002).

The same potential issues and impact arise within nursing. Depending on the clinical setting and other variables, anywhere from 33 to 44\% (Potter et al. 2010), and upward of $86 \%$ of nurses (Hooper et al. 2010), show significant signs of compassion fatigue and burnout. Chaplains are in a critical unique position to provide spiritual and emotional support to nursing staff. Additionally, they often have the added benefit of empathizing with colleagues given they are more closely experiencing the same clinical setting and intensity as nurses. Therefore, chaplains, in providing proactive spiritual and emotional support to physicians, nurses and other staff, can potentially positively contribute to an institution's fiscal considerations by addressing and supporting positive coping strategies for healthcare professionals suffering burnout and have a positive impact on their engagement with their institutions and ultimately retention and turnover.

\section{Patient Cost Benefits}

Addressing patients' spiritual distress and supporting their resiliency enhances their overall satisfaction with received hospital care, critically important given patient satisfaction-including access, outcome, timeliness and effectiveness of service provided, among other metrics - is a major driver of US federal healthcare reimbursement (Petrullo et al. 2013). Patients unable to have their spiritual needs adequately addressed are more likely to have lower satisfaction with, and perception of, care quality (Astrow et al. 2014). Moreover, addressing spiritual concerns not only positively impacts overall patient satisfaction but also increases trust in the medical team (Williams et al. 2011).

It has also been found that patients receiving less than adequate spiritual support generate higher care costs, spending less time in hospice and having more aggressive and costly ICU care. Quantifying the cost savings, in 2010 US dollars, one study estimated these as $\$ 2114$ per patient, with greater savings for minority patients (\$4257) and 'high religious copers' (\$3913) (Balboni et al. 2011). Moreover, congestive heart failure patients who experience spiritual struggle also have poorer physical function and increased hospitalizations (Park et al. 2011), while a study by Duke University Medical Center revealed religious struggle is a predictor of mortality in medically ill elderly patients (Pargament et al. 2001).

Additionally, palliative care programs, which place a central focus on spiritual care provision for patients and their families, when compared to patients not receiving palliative care services, contribute to a cost savings, in 2008 US dollars, of $\$ 1696$ in direct costs per admission for patients who are discharged and \$4908 per admission for patients who die in the hospital (Morrison et al. 2008). If a spiritual care specialist - a board-certified chaplain-works with palliative care and nonpalliative care patients during their hospitalization, they could help mitigate some of the severity of the health outcomes research demonstrates is related to spiritual distress. In doing so, the chaplain has the potential to positively impact the bottomline of the institutions providing that care. 


\section{Challenges to Spiritual Care Financial Benefits}

There are two primary stumbling blocks to reaping the financial benefits of spiritual care provision in the US healthcare system. First, spiritual care is not reimbursed from US federal taxes, where the constitution's first amendment requires the separation of church and state. Health facilities therefore have to compensate for this regulatory barrier by funding such un-reimbursable care from less reliable patient, private and public sources (Warnock 2009).

Second, when healthcare costs are a substantial portion of public and private budgetary expenditures, there is an imperative to use validated instruments to generate quantifiable evidence demonstrating the effectiveness, efficacy, appropriateness and acceptability of spiritual care services. These instruments should include those that can screen people for spiritual distress, assess their needs and determine the impact of spiritual interventions on patient outcomes. Currently, however, there is a relative lack of such tools, a deficiency that needs to be addressed.

\section{Conclusions}

Spirituality and religion have been central to the lives of the vast majority of Americans (Newport 2016). Research suggests spirituality remains relevant to the pursuit of optimal healthcare provision. However, there is a need to explore further the benefits of effective spiritual care provision for the US health system, not only in terms of health and satisfaction outcomes among patients and their families, but also critically in terms of their potential economic benefits, adding to the current reforms package aimed at minimizing US healthcare costs and saving federal dollars.

From a policy perspective, it is clear there are two issues that need to be addressed if those goals are to be achieved. First, the most effective pathway to achieving a reliable spiritual care financing scheme is to explore its provision in a bundled, or episode-based, payment model. Entailing payments on the basis of expected costs for clinically defined episodes of care, such an option would negate the need to designate chaplains as official healthcare providers who can bill for their services. This would enable economic evaluations of spiritual care interventions which, as in palliative care generally (Mathew et al. 2020), are lacking.

Second, while there is an increasing drive to develop, refine and validate spiritual care tools-domain-specific measurements exist that address patient screening, history taking and assessment (Emanuel et al. 2015; Drummond and Carey 2019), with varying degrees of validation - there is a need to invest in the development of spiritual care outcome instruments that are reliable and valid across varying settings, patient demographic profiles and diagnostic groups. In addition to providing rigorous evidence of the impact of spiritual care interventions on patients and their families, such work would also help more efficiently target spiritual care interventions and inform a meaningful dialogue on US healthcare reimbursement and bottomline cost savings. 
Acknowledgements Mr Powell's independent contribution to this article is supported by the National Institute for Health Research Applied Research Collaboration Northwest London. The views expressed in this publication are those of Mr Powell and not necessarily those of the National Institute for Health Research or the Department of Health and Social Care.

\section{References}

Astrow, A. B., Fromer, N., Sambidi, S., Kwok, G., Sharma, R., \& Sulmasy, D. (2014). Spiritual needs and patient satisfaction in multi-cultural patient population. Journal of Clinical Oncology, 33(suppl 15), e20562-e20562.

Balboni, T., Balboni, M., Paulk, M. E., et al. (2011). Support of cancer patients' spiritual needs and associations with medical care costs at the end of life. Cancer, 117, 5383-5391.

Balboni, T. A., Vanderwerker, L. C., Block, S. D., et al. (2007). Religiousness and spiritual support among advanced cancer patients and associations with end-of-life treatment preferences and quality of life. Journal of Clinical Oncology, 25, 555-560.

Drummond, D. A., \& Carey, L. B. (2019). Assessing spiritual well-being in residential aged care: An exploratory review. Journal of Religion and Health, 58 (2), 372-390. https://doi.org/10.1007/s1094 3-018-0717-9.

Emanuel, L. L., Powell, R. A., Handzo, G., Michelson, K. N., \& Dhingra, L. (2015). Validated assessment tools for psychological, spiritual and family issues. In N. Cherny, M. Fallon, S. Kaasa, R. K. Portenoy, \& D. C. Currow (Eds.), Oxford Textbook of Palliative Medicine (5th ed., pp. 398-406). Oxford: Oxford University Press.

Flannelly, K. J., Emanuel, L. L., Handzo, G. F., Galek, K., Silton, N. R., \& Carlson, M. (2012). A national study of chaplaincy services and end-of-life outcomes. BMC Palliative Care, 11, 10.

Herman, B. America's health care economy keeps ballooning. (2019). Axios. Retrived April 25, 2019, from https://www.axios.com/health-care-spending-2018-hospitals-doctors-drugs-economy-b5209 30a-0cd9-4c68-9dd1-f31cc08ec264.html. Published February 21, 2019.

Hills, J., Paice, J. A., Cameron, J. R., \& Shott, S. (2005). Spirituality and distress in palliative care consultation. Journal of Palliative Medicine, 8, 782-788.

Hooper, C., Craig, J., Janvrin, D. R., Wetsel, M. A., \& Reimels, E. (2010). Compassion satisfaction, burnout, and compassion fatigue among emergency nurses compared with nurses in other selected inpatient specialties. Journal of Emergency Nursing, 36, 420-427.

Kamal, A. H., Wolf, S. P., Troy, J., et al. (2019). Policy changes key to promoting sustainability and growth of the specialty palliative care workforce. Health Affairs (Millwood), 38, 910-918.

Larson, D. B., \& Larson, S. S. (2003). Spirituality's potential relevance to physical and emotional health: A brief review of quantitative research. Journal of Psychology and Theology, 31, 37-51.

Lumb, P. D. (2016). Burnout in critical care healthcare professionals: Responding to the call for action. Critical Care Medicine, 44, 1446-1448.

Mathew, C., Hsu, A. T., Prentice, M., et al. (2020). Economic evaluations of palliative care models: A systematic review. Palliative Medicine, 34, 69-82.

Morrison, R. S., Penrod, J. D., Cassel, J. B., et al. (2008). Cost savings associated with US hospital palliative care consultation programs. Archives of Internal Medicine, 168, 1783-1790.

Newport, F. (2016). Most Americans still believe in God. Social \& Policy Issues, Gallup. Retrived April 15, 2019, from https://news.gallup.com/poll/193271/americans-believe-god.aspx?utm_source=alert \&utm_medium=email\&utm_content=morelink\&utm_campaign=syndication. Published June 29, 2016.

Organization for Economic Co-operation and Development. (2017). Health at a glance - 2017: OECD Indicators. Paris: OECD Publishing.

Pargament, K. I., Koenig, H. G., Tarakeshwar, N., \& Hahn, J. (2001). Religious struggle as a predictor of mortality among medically ill elderly patients: A 2-year longitudinal study. Archives of Internal Medicine, 161, 1881-1885.

Park, C. L., Wortmann, J. H., \& Edmondson, D. (2011). Religious struggle as a predictor of subsequent mental and physical well-being in advanced heart failure patients. Journal of Behavioral Medicine, $34,426-436$. 
Petrullo, K. A., Lamar, S., Nwankwo-Otti, O., Alexander-Mills, K., \& Viola, D. (2013). The patient satisfaction survey: What does it mean to your bottom line? Journal of Hospital Administration, 2, 1-8.

Potter, P., Deshields, T., Divanbeigi, J., et al. (2010). Compassion fatigue and burnout: Prevalence among oncology nurses. Clinical Journal of Oncology Nursing, 14, E56-E62.

Puchalski, C. M., Vitillo, R., Hull, S. K., \& Reller, N. (2014). Improving the spiritual dimension of whole person care: Reaching national and international consensus. Journal of Palliative Medicine, 17, 642-656.

Ratanawongsa, N., Roter, D., Beach, M. C., et al. (2008). Physician burnout and patient-physician communication during primary care encounters. Journal of General Internal Medicine, 23, 1581-1588.

Sawyer B, McDermott D. (2019). How does the quality of the U.S. healthcare system compare to other countries? Peterson-Kaiser Health System Tracker. Retrived April 25, 2019, from https://www.healt hsystemtracker.org/chart-collection/quality-u-s-healthcare-system-compare-countries/\#item-start. Published March 28, 2019.

Shanafelt, T. D., Bradley, K. A., Wipf, J. E., \& Back, A. L. (2002). Burnout and self-reported patient care in an internal medicine residency program. Annuals of Internal Medicine, 136, 358-367.

Sisko, A. M., Keehan, S. P., Poisal, J. A., et al. (2019). National Health Expenditure Projections, 201827: Economic and demographic trends drive spending and enrollment growth. Health Affairs (Millwood), 38, 491-501.

Spickard, A., Jr., Gabbe, S. G., \& Christensen, J. F. (2002). Mid-career burnout in generalist and specialist physicians. Journal of the American Medical Association, 288, 1447-1450.

Warnock, C. J. P. (2009). Who pays for providing spiritual care in healthcare settings? The ethical dilemma of taxpayers funding holistic healthcare and the first amendment requirement for separation of church and state. Journal of Religion and Health, 48, 468-481. https://doi.org/10.1007/s1094 3-008-9208-8.

Williams, J. A., Meltzer, D., Arora, V., Chung, G., \& Curlin, F. A. (2011). Attention to inpatients' religious and spiritual concerns: predictors and association with patient satisfaction. Journal of General Internal Medicine, 26, 1265-1271.

Publisher's Note Springer Nature remains neutral with regard to jurisdictional claims in published maps and institutional affiliations. 